\title{
Histological Studies of the Effects of Aeromonas salmonicida on the Tissues in Brachymystax lenok
}

Shaowu $\mathrm{Li}^{1}$, Gefeng $\mathrm{Xu}^{2}$, Di Wang ${ }^{1}$, Zhenbo Mou ${ }^{1}$ and Tongyan $\mathrm{Lu}^{1^{*}}$

${ }^{1}$ Heilongjiang River Fisheries Research Institute, Chinese Academy of Fishery Sciences, Harbin, PR China

${ }^{2}$ College of Animal Science and Technology, Northeast Agricultural University, Harbin, PR China

"Corresponding author: Tongyan Lu, Heilongjiang River Fisheries Research Institute, Chinese Academy of Fishery Sciences, Harbin, PR China, Tel: +86-451-84604803, E-mail: lutongyan@hotmail.com

Rec date: Nov 22, 2014, Acc date: Nov 24, 2014, Pub date: Nov 26, 2014

Copyright: (c) $2014 \mathrm{Li} \mathrm{S}$, et al. This is an open-access article distributed under the terms of the Creative Commons Attribution License, which permits unrestricted use, distribution, and reproduction in any medium, provided the original author and source are credited.

\section{Introduction}

Furunculosis caused by Aeromonas salmonicida occurred frequently in farm-raised Brachymystax lenok recently and affected the healthy development of cold-water fish aquaculture in China. In this study, the effect of a pathogenic strain A. salmonicida (LN1301) on four tissues (including liver, spleen, kidney and intestine) of fish was investigated. LN1301 was originally recovered from liver of diseased juvenile Brachymystax lenok with septicemia signs. Artificial infection proved that LN1301 was highly virulent to fish when challenged by wounded immersion or intraperitoneal injection. Healthy juvenile Brachymystax lenok (body weight of $90 \mathrm{~g}-100 \mathrm{~g}$ ) were used for virulence assays and observation of histological changes. The experimental fish were randomly assigned into treatment group $(n=3)$ and control group $(n=3)$. The fish in the treatment group was intraperitoneal injected with LN1301 strain at a dosage of $1 \times 10^{6} \mathrm{CFU}$ and the control fish received equal amounts of distilled water. The fish which exhibited clinical signs were then sacrificed and the tissues were taken carefully and fixed quickly into the Bouin's solution for routine histological procedures. The results indicated that there were obvious histological changes in several tissues of LN1301 infected fish. As shown in Figure 1A, hepatic cells degenerated, cytoplasm became loosened, lots of lymphocytes infiltrated, amounts of erythrocytes increased in in liver. Regarding the spleen, parenchyma cells dissolved, nucleus enlarged and the cytoplasm became loosened (Figure 1B). In the kidney of diseased fish, epithelial cells appeared hydropic degeneration and separated from the basement membrane. Glomeruli was swelled and arranged in disorder with the increasing of the cystic cavity gap (Figure 1C). There was no obvious boundary among the layers of intestinal mucosa (Figure 1D).

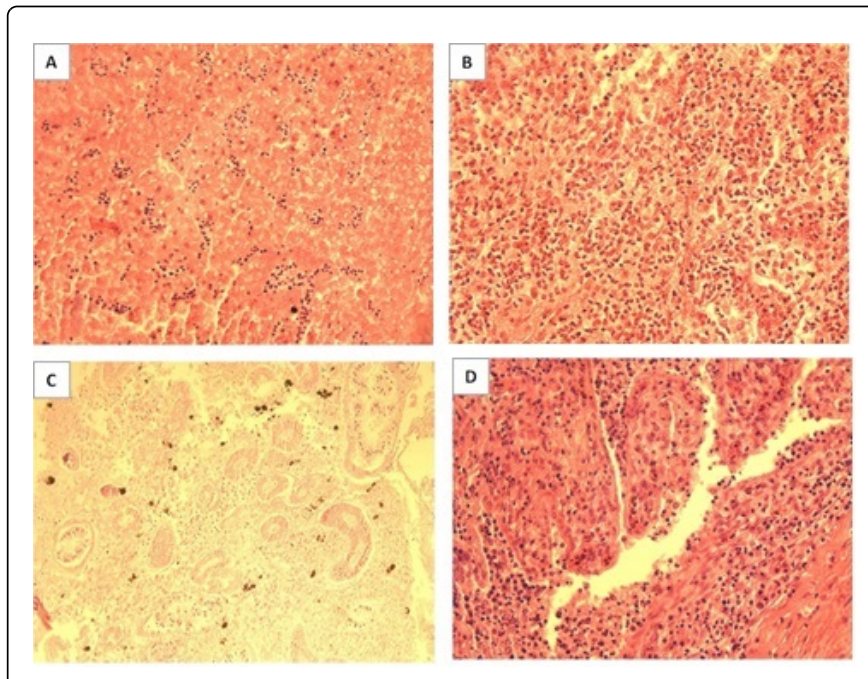

Figure 1: Photomicrographs of a section of four tissues of Brachymystax lenok challenged by A. salmonicida strain LN1301. A: Liver (400x); B: Spleen $(400 \times)$; C: Kidney $(200 \times)$; D: Intestine $(400 \times)$.

\section{Acknowledgement}

This work was supported by grants from Special Scientific Research Funds for Central Non-profit Institutes, Chinese Academy of Fishery Sciences (2014A06XK05) and National "Twelfth Five-Year" Plan for Science \& Technology (2012BAD25B10). 